\title{
LA IMPLEMENTACIÓN DE LA DIRECTIVA MARCO DEL AGUA EN LAS REGIONES DEL FRIULI VENEZIA GIULIA Y LA COMUNIDAD VALENCIANA: ESTADO DE LA CUESTIÓN ${ }^{1}$
}

\author{
María Hernández Hernández \\ Departamento de Análisis Geográfico Regional y Geografía Física (Universidad de Alicante) \\ Andrea Guaran \\ Departamento de Economía, Sociedad y Territorio (Universidad de Udine)
}

\section{RESUMEN}

La directiva 2000/60/CE es una normativa europea por la que se establece un marco de actuación comunitario en el ámbito de la política de aguas. Atendiendo a los objetivos y fases de ejecución de la citada directiva marco, esta investigación pretende analizar cómo se ha articulado el proceso de implementación de la normativa comunitaria y la elaboración de aquellos documentos que ésta requiere en dos regiones comunitarias (la Valenciana y la del Friuli Venezia Giulia). Con ello, se trata de diagnosticar las dificultades derivadas de su implementación en ámbitos con estructuras físico-ecológicas y socio-económicas diversas y en las que el recurso agua tiene significados y valores diversos.

Palabras clave: directiva marco del agua, Comunidad Valenciana, Friuli Venezia Giulia, agua, demarcación hidrográfica, gestión y protección del agua, Júcar, Tagliamento.

1 Este artículo se enmarca en la investigación desarrollada en la Universidad degli Studi Udine (Italia) financiada por la Conselleria de Empresa, Universidad y Ciencia de la Generalitat Valenciana (Programa «Becas para estancias de profesores e investigadores fuera de la Comunidad Valenciana». Convocatoria 2006). 


\begin{abstract}
Directive 2000/60/EC of the European Parliament establishes a framework for community action on water policy. Attending to the aims and execution of this directive, this research tries to analyze how the implementation process and achievement of documents that this one requires are articulated in two community regions (Valencian and Friuli Venetia Giulia). With this analysis, it is diagnosed difficulties derived from the application of a common regulation in areas with diverse physic-ecological and socio-economic structures and where the resource water has different meanings and values.
\end{abstract}

Key words: Water Framework Directive, Valencia Region, Friuli Venetia Giulia Region, water, river basin districts, water protection and management, Jucar, Tagliamento.

\title{
1. INTRODUCCIÓN
}

La directiva 2000/60/CE propugna un «nuevo modelo de gestión de los recursos hídricos» al amparo de los planteamientos de desarrollo sostenible, recogidos en el Tratado de Ámsterdam (1999). Para ello, se apuesta por la adopción de unas directrices orientadas a la aplicación de políticas que promuevan una adecuada gestión del agua como recurso y de los ecosistemas y paisajes vinculados a ella, por la sustitución de la política hidráulica tradicional (generación de recursos) por otras orientadas a la planificación de la demanda y por una visión holística y ecosistémica del agua, entendida no como un mero recurso económico, sino como portadora de valores de tipo ambiental, social y cultural. La consecución de tales premisas se articula en cuatro grandes objetivos, a saber: la definición de las aguas europeas y sus características, el establecimiento de un marco de protección de las «masas de agua», la adopción de planes de gestión y la repercusión de los costes de los servicios hídricos. Para alcanzar los cuatro objetivos formulados, esta normativa se articula en tres fases de ejecución. Una primera etapa ha consistido en la individualización de las denominadas «demarcaciones hidrográficas», que, grosso modo, corresponden con las «confederaciones hidrográficas» o «bacini idrografici», según terminología española e italiana, respectivamente. Una segunda fase corresponde a la elaboración de un documento que responda a los requerimientos de los artículos 5 y 6 de la directiva. Este documento es fundamental para proceder, posteriormente (tercera fase), a la elaboración de los planes de gestión de cada demarcación hidrográfica.

Atendiendo a sus objetivos y fases de ejecución, esta investigación pretende analizar cómo se ha articulado la implementación de esta directiva marco en la Comunidad Valenciana (España) y en la región italiana del Friuli-Venezia-Giulia 
y más concretamente como se llevado a cabo el proceso de su transposición a las leyes nacionales y regionales y cómo se han elaborado aquellos documentos que ésta propone en sus diversos artículos, particularmente el 5 . El área de estudio son dos territorios de la Europa Mediterránea, la Comunidad Autónoma de Valencia (España) y la región italiana del Friuli Venezia Giulia (fig. 1). Ambas, si bien se integran en el ámbito mediterráneo, presentan unas estructuras físico ecológicas diversas. Igualmente, las estructuras económicas muestran unos rasgos comunes (sociedades postproductivistas), pero una breve aproximación a las actividades agrícolas y las turístico-residenciales pondrá de manifiesto rasgos contrastados como consecuencia de las diferencias físico-ecológicas. El análisis, aunque sucinto de ambas estructuras, evidenciará la diversidad de recursos disponibles, de valores y presiones que cada región ejerce sobre el recurso agua. Igualmente, nos permitirá comprobar cómo estos elementos son recogidos por las normativas vigentes y cómo se plasman en los nuevos documentos requeridos por la Directiva Marco del Agua. También el estudio de los usos agrícolas y turísticos y, especialmente, la evolución de las demandas ejemplifican las relaciones que se establecen entre ellas y los posibles conflictos en el acceso al agua.

El área de estudio son las regiones de Valencia y del Friuli Venezia Giulia (fig. 1) y más específicamente las cuencas hidrográficas que interesan a estos territorios. Su elección, no obstante, requiere una serie de precisiones. Esta escala se justifica por el hecho de que es la cuenca hidrográfica la entidad responsable de la aplicación de esta normativa y de la elaboración de la documentación que ésta precisa. Sin embargo, se superpone a una de tipo administrativo (regiones político-administrativas), que es en ultima instancia, en realidad, los políticos, la que controla los órganos de gestión de estas entidades; condicionando los tiempos y las formas de aplicación. Igualmente, es la escala regional y no la demarcación hidrográfica en la que se presentan un gran número de indicadores de tipo físico y socio-demográfico necesarios para evaluar la trascendencia que el recurso agua tiene en ambos territorios y cómo éstos condicionan la implementación de esta directiva. Se ha considerado que la superposición de ambas escalas (políticoadministrativa e hidrográfica) es la metodología más adecuada para lograr los objetivos de esta investigación; aunque ello conlleve la no coincidencia de ambas; si bien se trata de hacer corresponder al máximo las dos. En la Comunidad Valenciana, la cuenca elegida es la del Júcar, que abarca el 91,6\% del territorio regional (Confederación Hidrográfica del Júcar, 1999). En la región italiana, conciliar ambos niveles es más complejo: comprende una demarcación de relevancia nacional como es la de los ríos Tagliamento, Isonzo y Livenza, un conjunto de pequeñas cuencas que son administradas por el gobierno regional y un curso de agua (Slizza) que forma parte de una demarcación internacional, al ser afluente 
del Danubio, pero gestionada por la Autorità di Bacino Regionale. Siendo objeto de atención en este artículo las dos primeras, al afectar al 98\% del territorio regional (Regione Autonoma Friuli Venezia Giulia, 2007a). A la complejidad de superponer dos escalas diversas, se añade las dificultades de comparar corpus normativos diversos, entidades de gestión y planificación hídrica con objetivos y competencias diversas, etc. No obstante, este es, también, un valor añadido, ya que corrobora la complejidad de implementar normativas de ámbito comunitario en regiones con realidades físico-ecologías y socio-económicas diversas.

Figura 1. Localización de las áreas de estudio. Elaboración propia
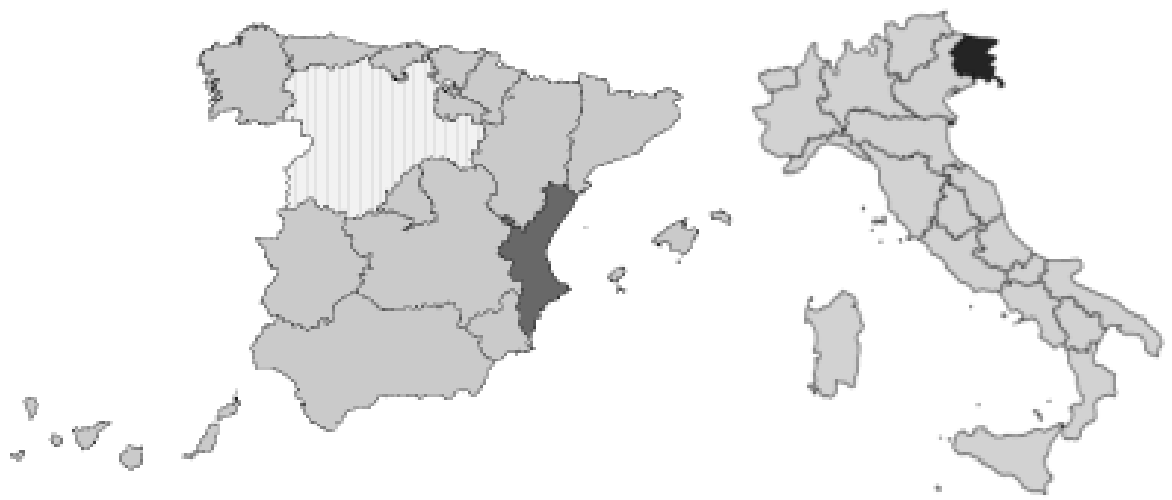

La hipótesis de partida de esta investigación era corroborar si la denominada «estrategia común de implantación», uno de los elementos novedosos de esta directiva, estaba condicionada, por un lado, por los marcos legales pre-existentes y, por otro, por las estructuras físico-ecológicas y las socio-económicas de ambos ámbitos de estudio, que pudieran asignar diferentes valores y presiones sobre el recurso agua. Se trataba, asimismo, de poner de manifiesto las posibles dificultades y debilidades de este proceso; pero también de aquellos puntos fuertes. Aquéllas atendiendo a una serie de factores, entre los que cabía citar la existencia de organismos varios con implicaciones en la gestión y planificación del recurso agua, la asignación de funciones diversas a estos organismos, la disponibilidad de información estadística, etc. Éstas, relacionadas con la participación activa de las partes interesadas, la disponibilidad de documentación común sobre el recurso agua, entre otras. El disponer de una información más completa, tanto desde el punto de vista técnico, como de los procesos de elaboración de los documentos requeridos y la participación pública fue considerado como un factor que podría contribuir a mejorar la implementación de esta normativa y de otras a medio y largo plazo. 
Para la consecución de los objetivos previstos, se ha recurrido al análisis y consulta de fuentes documentales tanto directas como indirectas (bibliografía sobre el proceso de implementación de la directiva marco del agua). Entre las primeras, cabe citar los diversos documentos elaborados por las entidades (planes hidrológicos de cuenca, informes para la implantación de la DMA, etc.), fuentes estadísticas varias elaboradas por organismos públicos de ambas regiones (censos agrarios, oferta hotelera, consumos de agua, entre otras) y la realización de entrevistas a aquellos agentes que tienen una participación activa, bien como usuarios (comunidades de regantes, agricultores, asociaciones de hoteleros, empresas y consorcios de gestión en baja del agua potable) o como gestores (técnicos de las confederaciones hidrográficas). La realización de entrevistas, además de proporcionar información relativa a usos y demandas de recursos hídricos, permite poner de manifiesto el grado de participación de los diversos colectivos en la implementación de esta normativa comunitaria. No como un mero agente pasivo, sino evaluando su nivel de implicación en las diversas fases de activación y aplicación, es decir, nos permitió no sólo conocer si habían tenido acceso a la información y al tipo de información disponible, sino también si habían participado activamente en las políticas de gestión y planificación. El análisis de los documentos elaborados hasta el momento para la implantación de la directiva marco, concretamente el informe del artículo 5, por las respectivas autoridades de las cuencas hidrográficas interesadas nos permite reflexionar sobre las implicaciones que las diferencias socioeconómicas y territoriales en ambas regiones tienen en el tratamiento del recurso agua y cómo éste se plasma en la información que éstos contienen. En este nivel de documentación, cabe establecer una diferenciación entre la Comunidad Valenciana donde se analiza un único borrador ya que el Júcar cubre más del 90\% de la superficie regional, frente a los dos objeto de estudio para la región del Friuli, para cubrir una porcentaje de superficie regional significativo. Han sido objeto de estudio, asimismo, los marcos de planificación vigentes en los diversos ámbitos objeto de estudio, al ser los documentos de partida para la elaboración del «report del artículo 5». En este último, han sido objeto de estudio una serie de variables (análisis económico del agua, recursos y demandas, y calidad de las aguas), que sintetizan los objetivos principales perseguidos por la directiva comunitaria.

\section{EL ÁREA DE ESTUDIO: DOS REGIONES CON UNAS ESTRUCTURAS FÍSICO-ECOLÓGICAS Y SOCIOECONÓMICAS DIVERSAS}

El acusado desarrollo latitudinal, en combinación con la configuración del relieve y el singular trazado del litoral, propician que la tierras valencianas ofrezcan una notoria diversidad climática e hidrogeográfica, que se traduce en apreciables diferencias térmicas, pluviométricas y de disponibilidad de agua. Salvo las dos Marinas, la Safor y algunos islotes lluviosos en los re- 
lieves del noroeste de Castellón y norte de Alicante, donde se alcanzan los $700 \mathrm{~mm}$ de precipitación, en el resto del territorio apenas se superan los $400 \mathrm{~mm}$, y descienden por debajo de este umbral en las comarcas meridionales alicantinas (Rico y Hernández, 2008). Específicamente, el área litoral se caracteriza por un clima mediterráneo en el que las temperaturas medias se sitúan entre 17 y $19^{\circ} \mathrm{C}$ en función de un verano caluroso con valores entre 24 y $26^{\circ}$ y un invierno tibio y libre de heladas, con medias para enero entre 9 y $11^{\circ} \mathrm{C}$ (Pérez, 1994). El régimen pluviométrico, determinado por el predominio de unos climas de filiación mediterránea, motiva el régimen de los cursos fluviales autóctonos que se caracterizan por caudales relativos ínfimos, fuerte irregularidad interanual y durísimos estiajes veraniegos. Su eficacia, desde el punto de los recursos hídricos, se ve reducida por su carácter torrencial y su cercanía al mar. Los mayores volúmenes de agua son aportados por los cursos alóctonos (Turia, Segura y Júcar), que proporcionan alrededor del 60\% del agua disponible en la región (Morales, Rico y Hernández, 2005).

Frente al clima valenciano donde la aridez y la elevada evapotranspiración potencial son algunos de sus rasgos definidores, la región del Friuli Venezia Giulia, situada en el extremo nororiental de Italia, presenta como principal rasgo definidor su naturaleza montañosa (el 42,5\% de su superficie aparece interesada por las estructuras alpinas y prealpinas). Latitud y altitud condicionan un clima que, grosso modo, puede ser definido como fresco o frío según las diferentes subregiones. Las precipitaciones son abundantes: se superan los $1.000 \mathrm{~mm}$. prácticamente en toda la región, con valores máximos en el área prealpina giuliana donde se alcanzan los $3.000 \mathrm{~mm}$ (ISTAT, 2005a). Las copiosas precipitaciones y la innivación garantizan un elevado aporte hídrico a los numerosos ríos que discurren por la región y contribuyen a recargar la falda freática. De este hacia oeste, las principales cuencas hidrográficas son las del Isonzo $\left(1.150 \mathrm{Km}^{2}\right.$ en territorio italiano y con un caudal medio de $170 \mathrm{~m}^{3} / \mathrm{seg}$.), río internacional ya que parte de su curso discurre por Eslovenia, el Tagliamento $\left(2.900 \mathrm{Km}^{2}\right.$ y con un caudal medio de $70 \mathrm{~m}^{3} / \mathrm{seg}$.) que recoge casi la práctica totalidad de las aguas del sector alpino regional y el Livenza $\left(2.200 \mathrm{Km}^{2}\right)$, a caballo entre esta región y la del Veneto. El Corno y el Cormor, junto a otros cursos fluviales de menor entidad, configuran la denominada «zona hidrográfica central», entre el río Tagliamento al oeste y el Isonzo al este, cuyos conos de deyección se sitúan en terrenos muy permeables de alta llanura. La baja llanura se caracteriza por un elevado número de pequeños cursos fluviales de surgencia («risorgive») que desembocan en el sector lagunar. 
Tabla 1. Cuadro-síntesis de las estructuras físico-ecológicas y socioeconómicas de las regiones del Friuli Venezia Giulia y la Comunidad Valenciana

\begin{tabular}{|c|c|c|}
\hline & Comunidad Valenciana & Friuli Venezia Giulia \\
\hline Superficie & $23.255 \mathrm{~km}^{2}$ & $7.856 \mathrm{~km}^{2}$ \\
\hline Precipitaciones (medias) & entre 400 y $700 \mathrm{~mm}$ & entre 1.500 y $1.600 \mathrm{~mm}$ \\
\hline $\begin{array}{l}\text { Temperaturas (medias): } \\
\text { - media enero } \\
\text { - media julio }\end{array}$ & $\begin{array}{l}9 \text { y } 10^{\circ} \text { (costa) } / 5-6^{\circ} \text { (interior) } \\
24 \text { y } 26^{\circ} \text { (costa) } / 23-21 \text { (interior) }\end{array}$ & $\begin{array}{c}1-3^{\circ} \mathrm{C} \\
21-22^{\circ} \mathrm{C}\end{array}$ \\
\hline $\begin{array}{l}\text { Población (2008) } \\
\text { Población (2001) } \\
\text { Población (1991) }\end{array}$ & $\begin{array}{l}5.029 .601 \\
4.162 .776 \\
3.857 .234\end{array}$ & $\begin{array}{l}1.210 .903 \\
1.183 .764 \\
1.197 .666\end{array}$ \\
\hline $\begin{array}{l}\text { Superficie cultivada } \\
\text { (2007) (ha) }\end{array}$ & $\begin{array}{l}719.800 \text { ha } / 340.298 \text { ha } \\
\text { (regadío) } \\
\text { - } 154.000 \text { cítricos } \\
\text { - } 35.000 \text { hortalizas } \\
\text { - } 28.000 \text { otros frutales }\end{array}$ & $\begin{array}{l}418.003 \text { ha } / 240.000 \text { ha } \\
\text { (regadío) } \\
\text { - } 175.532 \text { cereales } \\
\text { - } 41.715 \text { cult. industriales } \\
\text { - } 22.753 \text { leñosos }\end{array}$ \\
\hline $\begin{array}{l}\text { total plazas alojamiento } \\
\text { (2007) } \\
\text { - plazas hoteleras } \\
\text { viajeros (millones) } \\
\text { pernoctaciones (millones) }\end{array}$ & $\begin{array}{l}325.405 \\
\cdot 127.695 \\
9,2 \\
25,2\end{array}$ & $\begin{array}{l}150.462 \\
\cdot 38.191 \\
1,8 \\
8,4\end{array}$ \\
\hline
\end{tabular}

Fuentes: Comunidad Valenciana (Pérez, 1994; INE, 2001, 2005 y 2009; Agencia Valenciana de Turismo, 2009). Región del Friuli Venezia Giulia (ISTAT, 2005a, 2005b y 2007b; Regione Autonoma Friuli Venezia Giulia, 2003 y 2007a). Elaboración propia

La Comunidad Valenciana es, con 5.029.601 habitantes, la cuarta comunidad autónoma por población (11,51\% del total nacional). Durante la segunda mitad del pasado siglo y primeros años del presente, ha experimentado un fuerte desarrollo demográfico al pasar de 2.256.507 habitantes, según el censo de 1960, a los 5.029.601 a 31 de diciembre de 2008 (INE, 2009). Éste viene determinado por el crecimiento natural y la llegada de población emigrante tanto comunitaria como extra-comunitaria. Los procesos de urbanización, industrialización y desarrollo turístico han determinado la concentración del $77 \%$ de la población valenciana en el eje litoral.

La llegada de población extranjera es también una dinámica reciente en la región italiana. Ésta, proveniente, sobre todo, de los Balcanes dada su cercanía, ha introducido un importante rejuvenecimiento a una sociedad, caracterizada por su elevada tasa de envejecimiento resultado de una alta esperanza de vida, unas bajas tasas de natalidad y una importante tasa de emigración que registró desde el final de la II Guerra Mundial hasta principio de los años 80 del siglo pasado. Esta dinámica regresiva se ha invertido en los últimos años: frente a una pérdida cifrada en unos 50.000 habitantes en el periodo intercensal 1981- 
2001, desde este año se observa una leve recuperación (ISTAT, 2005b). Esta región, que ocupa el 2,6\% del territorio nacional y el 2\% de su población, es decir, poco más de un 1.200.000 habitantes, se caracteriza, desde el punto de vista del modelo territorial, por una fuerte polarización en las provincias de Udine, que concentra la mitad de la población regional, y en la de Trieste, que reúne en la ciudad homónima la casi totalidad de los 240.000 habitantes censados, frente a la escasos 350.000 de las otras dos provincias (Gorizia y Pordenone).

La disparidad de recursos disponibles (INE, 2008 e ISTAT 2006 y 2007a), consecuencia de unas condiciones físico-ecológicas diversas, no es impedimento para que ambas regiones hayan registrado una tendencia al alza en los consumos hídricos durante la segunda mitad del siglo XX debido, entre otras causas, a los cambios cualitativos y cuantitativos experimentados por las diferentes demandas. En los urbanos, el número de usuarios y habitantes conectados a las redes de abastecimiento de agua potable, ha experimentado un fuerte incremento durante todo el siglo XX en gran medida como resultado de las mejoras en los sistemas de abastecimiento y en el consumo de agua por habitante y día. En el año 2007, sin contabilizar el poblamiento estacional de veraneantes y turistas y teniendo en cuenta que la demanda bruta por habitante se situó en 170 1/día (INE, 2008), el consumo ascendería a unos 428 $\mathrm{hm}^{3}$ en la Comunidad Valenciana. En el Friuli, las demandas urbanas suman, aproximadamente, unos $200 \mathrm{hm}^{3}$ como resultado de una demanda bruta por habitante y día de unos 280 litros (ISTAT, 2007a). La disponibilidad de recursos es una de las razones que justifica el mayor módulo de consumo por habitante y día, uno de los más altos de Italia, al igual que un volumen de pérdidas en red elevado. La mejora de los sistemas de distribución en baja en la Comunidad Valenciana, sobre todo, en los litorales donde la efectividad de las redes se sitúa alrededor del 90\%, y las campañas de ahorro, que han reducido los módulos de consumo desde los 2501/hab/día de principios de los años noventa, explica, que a pesar del notable incremento poblacional que ha registrado en el último intercensal, las demandas hídricas se hayan contenido.

Ambas regiones se enmarcan en las denominadas sociedades postproductivistas, es decir, aquéllas en las que el sector terciario ocupa a la mayor parte de la población activa, alrededor del 65\% tanto en Friuli como en Valencia. Ello no es óbice para que las actividades industriales y las agrarias tengan una honda presencia; caracterizándose ambas por el predominio de la pequeña y la mediana empresa en el sector manufacturero y el sistema de gestión familiar y la pequeña explotación en el primario. 
Los paisajes extensivos ocupados por cultivos cerealícolas y oleaginosas (soja) característicos de una agricultura continental (fig. 3, derecha) contrastan con una agricultura de tipo mediterráneo, donde predominan los aprovechamientos hortofrutícolas (fig.2, izquierda)

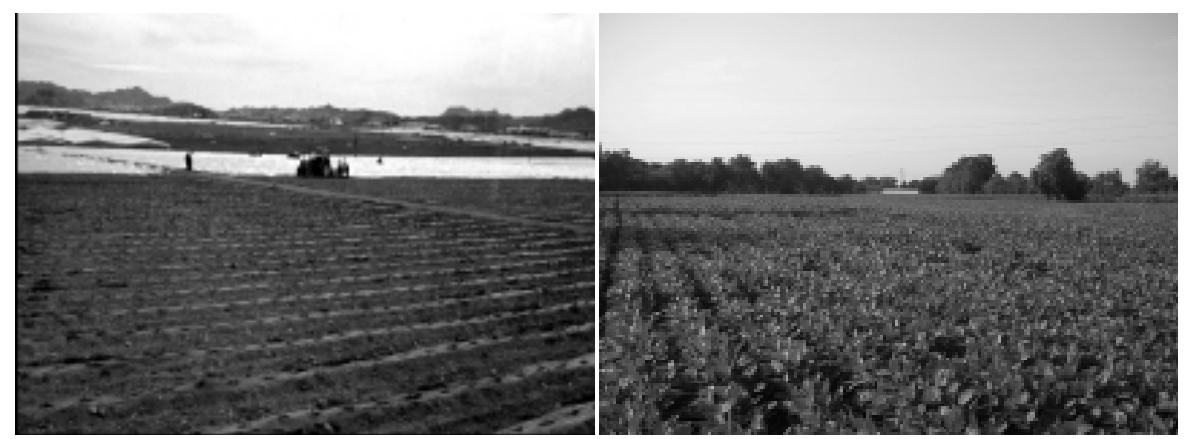

Estas similitudes encubren diferencias importantes desde el punto de vista de los aprovechamientos agrícolas y de las actividades turísticas. Cereales y olivos asociados a algunas hortalizas y tubérculos, que dominaba en la agricultura valenciana hasta finales del XIX, fueron paulatinamente sustituidos por cítricos y hortalizas con mayores exigencias de agua. En 2007, los regadíos valencianos sumaban 340.298 ha., alrededor del 49\% de la superficie total cultivada, de las que unas 154.000 correspondían a cítricos, unas 35.000 a hortalizas y unas 28.000 a otros frutales (Generalitat Valenciana, 2009), es decir, una agricultura de tipo mediterráneo y con una clara orientación hacia la exportación, especialmente la localizada en los sectores litorales (fig. 2). El incremento de las superficies regadas ha sido una constante en las tierras valencianas desde los años cincuenta hasta mediados de la década de los noventa. A partir de estos momentos, los regadíos registran un progresivo decrecimiento acentuado en la última década; lo que se ha traducido en una reducción de las demandas para uso agrícola (Rico y Hernández, 2008). Las causas que explican esta evolución se relacionan, en gran medida, con la expansión de los usos turístico-residenciales, dada la dura competencia que se establece entre agricultura de regadío y turismo, ya que ambos se localizan en las llanuras litorales. No hemos de olvidar factores estructurales inherentes al propio sector como puede ser la fragmentada estructura parcelaria, el envejecimiento de los activos o la escasez de recursos hídricos. Importantes resultan también los cambios registrados en la localización de las áreas regadas y de los sistemas de riego. De los regadíos históricos por gravedad se ha pasado, sobre todo a partir de la década de los años sesenta, a otros sistemas de derivación mediante potentes bombas que extraen las aguas de los acuíferos subterráneos y de las actuaciones hidráulicas como los trasvases Tajo-Segura y Júcar-Turia que 
han permitido captar aguas, elevarlas y conducirlas a terrenos muy alejados de los lechos de inundación; creándose nuevos espacios regados. La introducción y difusión de sistemas de manejo y ahorro de agua (riego por goteo) ha sido una de las características inherentes a estos nuevos regadíos y, recientemente, a los regadíos históricos a través de los Planes de Modernización de los regadíos (fig. 4). Según la Encuesta sobre el uso agrario del agua en el año 2007 (INE, 2008), las superficies regadas con sistemas de manejo de agua se sitúan alrededor del 50\% del total. Esta fuente documental pone de manifiesto, asimismo, el predominio de las aguas superficiales (66\%) frente a recursos subterráneos (29\%) y otros caudales (mayoritariamente, residuales depuradas) que concentran el 4\% de los recursos utilizados. Estos datos medios regionales encubren una gran diversidad a escala provincial. En Alicante, la escasez de recursos superficiales, se traduce en el predominio de los caudales subterráneos y la creciente utilización de caudales depurados y, recientemente, desalados.

Fig. 4 (izquierda) La construcción de embalses es una de las infraestructuras que permiten la sustitución del riego por gravedad por el de goteo y aspersión en el marco del Programa de Modernización de regadíos

Fig. 5 (derecha). Sistema de derivación del río Tagliamento origen del Consorcio Ledra-Tagliamento, una de las mayores entidades de riego del Friuli.
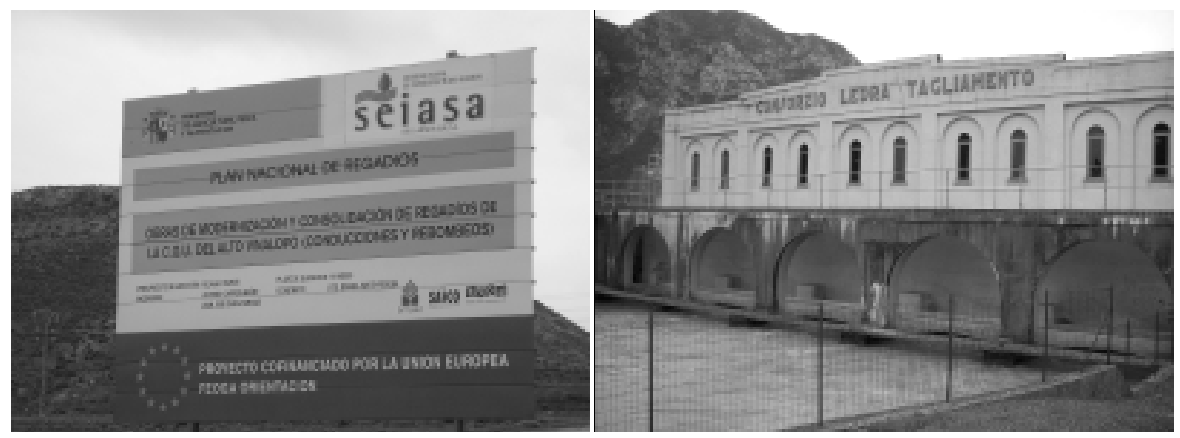

En la región del Friuli, los rasgos climáticos determinan el predominio de una agricultura de tipo continental (fig.3). De las 240.000 hectáreas en regadío, el 30\% de la superficie cultivada, el predominio corresponde a los aprovechamientos cerealícolas (maíz y, en menor medida, cebada forrajera y trigo) y a los cultivos industriales (remolacha azucarera y soja). Éstos, que concentran alrededor del $74 \%$ de la SAU se completan con la vid, de gran tradición histórica, a la que se une la introducción de frutales (manzanos, perales y, recientemente, el kiwi) (Regione Autonoma del Friuli, Venezia Giulia, 2003). El consumo agrícola de agua ha registrado unas mutaciones más contenidas en la región del Friuli. La 
superficie irrigada se ha mantenido estable en las últimas décadas, con un ligero incremento en la provincia de Udine, que es compensado por el leve decrecimiento experimentado en las otras provincias (Regione Autonoma Friuli, Venezia Giulia, 2006). Las grandes transformaciones se remontan a la primera mitad del siglo veinte cuando se puso en regadío gran parte de la alta llanura mediante la construcción de numerosas infraestructuras hídricas (canales y tomas de derivación de los principales cursos fluviales) y la constitución de las entidades que gestionan el agua como, por ejemplo, el Consorcio Ledra-Tagliamento (fig.5) y el Meduna-Cellina. Los aprovechamientos dominantes no han registrado tampoco grandes modificaciones: los herbáceos extensivos siguen siendo el paisaje dominante de esta región. Los principales cambios se vinculan a la sustitución de cereales (trigo por maíz y cebada forrajera) y la difusión cada vez mayor de los cultivos oleaginosos (soja, 37.000 ha. en 2000), con mayores requerimientos hídricos. La demanda agrícola, alrededor del 70\% del total, se vincula no tanto al total de superficie regada, sino a los módulos de consumo y a los sistemas de regadío. El cultivo mayoritario, el maíz (92.000 ha. en el año 2000, que corresponde al 38\% del total de la superficie cultivada), presenta unos módulos medios de consumo superiores a la media nacional. El sistema de regadío dominante, el riego por inundación, utilizado por el 90\% de las explotaciones agrícolas (Regione Autonoma Friuli, Venezia Giulia, 2006), contribuye al incremento de los consumos agrícolas. La abundancia de recursos y su escaso coste (en numerosas comunidades de regantes únicamente se paga un canon fijo de mantenimiento y no por el consumo real) explica que se riegue incluso cuando no es necesario. Los sistemas de manejo de agua (aspersión) son considerados, mayoritariamente por los agricultores, como inversiones costosas e innecesarias, salvo en periodos de sequía. Significativa resulta, asimismo, la procedencia del recurso: el 55\% de las explotaciones que recurren a sistemas de irrigación derivan el agua de los ríos y canales, el 31\% la extraen directamente del freático (pozos en la propia explotación) y el 24\% restante la obtiene de otras modalidades (acueducto, embalse para la recogida de aguas pluviales), en la que la utilización de aguas depuradas representa un porcentaje reducidísimo de las explotaciones $(0,15 \%)$.

Un segundo sector económico a considerar dadas las posibles repercusiones en el consumo hídrico son los usos turísticos. En el año 2008, el turismo generó un volumen de negocio de 13.502 millones de euros, el 8,9\% del valor añadido bruto del turismo español y el 12,1\% del producto interior bruto (Agencia Valenciana de Turismo, 2009). En 2008, la oferta de alojamiento ascendía a 325.405 plazas, de las que las 127.695 corresponden a hoteles. Éstas, que en 2008 acogieron 9,2 millones de viajeros y generaron algo más de 25 millones de pernoctaciones, suponen el 9,1\% del total nacional, lo que la sitúa a la región 
valenciana como tercer destino turístico nacional. Esta oferta se completa con la residencial integrada por viviendas y apartamentos no reglados, que suman alrededor de 2,2 millones de plazas (Vera, Casado y Ramón, 2004). Es la tipología de alojamiento dominante y pone de manifiesto el enorme peso del turismo residencial y del sector inmobiliario en la región valenciana (fig.6). La demanda de agua por el uso turístico-residencial presenta una tendencia al alza como consecuencia del incremento de las plazas hoteleras, pero, sobre todo, del boom en la construcción. En el quinquenio 2000-2005, se han creado unas 28.880 plazas hoteleras en las Comunidad Valenciana frente a las 8.500 de la década de los noventa. El proceso más espectacular ha sido, sin embargo, el notable desarrollo de la segunda residencia. En el intercensal de 1991 a 2001, el número total de viviendas de la región habría crecido de 2.094.033 unidades a 2.547.775, es decir, un saldo positivo de 453.742 unidades; ritmo que se ha acentuado desde el 2001 hasta el frenazo inmobiliario de 2007: los datos del Ministerio de Vivienda indican que entre 2003 y 2008, se habrían iniciado en la Comunidad Valenciana 438.875 nuevas viviendas.

La génesis del turismo en el Friuli se relaciona con la creación de la ciudad balneario de Grado en 1892 y la apertura de numerosos hoteles (Grado - figura 7 , izquierda). Los usos residenciales (figura 6, derecha) constituyen la tipología dominante en la Comunidad Valenciana

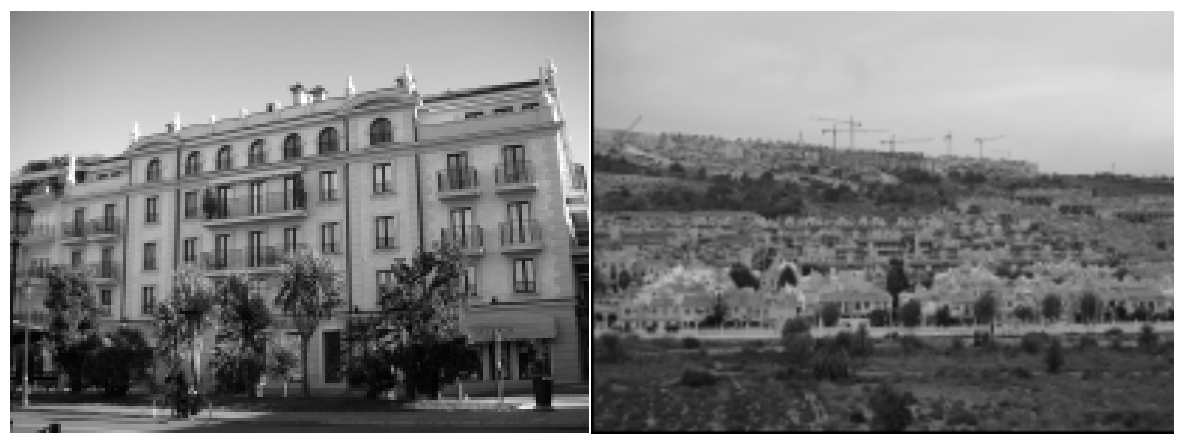

El desarrollo turístico del Friuli ha venido condicionado por su carácter continental y montañoso. La región cuenta con algunas localidades de renombre en el modelo de turismo de sol y playa (Grado -fig.7- y Lignano Sabbiadoro) que concentran más del $60 \%$ de las pernoctaciones del conjunto regional, que ascendieron a unos 8,4 millones en 2005, lo que representó únicamente el 2,3\% del total de la península itálica. El turismo estival se completa con las estaciones destinadas a la práctica de deportes de invierno en el área alpina y el cultural, que reunió el 15,3\% y el 13,2\% de las pernoctaciones, respectivamente (ISTAT, 
2007b). Los consumos turísticos en el Friuli presentan valores más reducidos, como resultado del número de visitantes, unos 2 millones, pero, sobre todo, por el menor volumen de vivienda secundaria (Battigelli, 2007). Según diversas fuentes, el consumo se situaría alrededor de 400 litros/persona/día, pero con valores incluso superiores a los 500 litros en el caso de los municipios con turismo litoral (Guaran, 2006). La tendencia en los últimos años viene definida por un mantenimiento de los consumos, en gran medida como resultado de la crisis que desde finales de la década de los ochenta han registrado los dos principales destinos turísticos de la región (Lignano y Grado) (Hernández, 2007; Guaran, 2007).

En Friuli, los principales puntos débiles del turismo, según ponen de manifiesto las entrevistas y encuestas realizadas, en relación a los recursos hídricos se relacionan con la demanda de calidad y su concentración en el periodo estival y, sobre todo, en algunos periodos y fechas concretas (Guaran, 2006). En cambio, unas demandas por encima de los recursos disponibles generan una fuerte competencia en la Comunidad Valenciana entre los consumos agrarios y los urbanoturísticos, para acceder a los recursos de mayor calidad y garantía de suministro. Esta competencia se ha planteado con una evidente desigualdad de fuerzas, en gran medida favorecida por la prioridad de uso que establece la Ley de Aguas (Art. 60, TRLA) para los suministros urbanos frente a los agrarios. Ello se ha dejado sentir en la evolución de las demandas de agua, con una dinámica de regresión en las agrarias frente a otra de intensificación en las urbano-turísticas (Rico y Hernández, 2008).

\section{LA PLANIFICACIÓN HIDROLÓGICA PREVIA A LA TRANSPOSICIÓN DE LA DIRECTIVA COMUNITARIA}

La planificación hidrológica presenta en ambos países una larga tradición. Las normativas se articulan alrededor de la definición del ámbito territorial de actuación y las competencias asignadas a los organismos encargados de la ejecución de estas actuaciones.

La gestión de los recursos hídricos en Italia se ha organizado en torno a dos campos de intervención diferenciados y, consiguientemente, de dos entidades con funciones específicas. Por un lado, las cuencas hidrográficas han sido administradas por la denominada «autorità di bacino», que tiene competencias en cuestiones relativas a la seguridad hidrológica, entendida en términos de prevención de inundaciones, sistematización de riberas y calidad de las aguas. La ley nacional 183/89 estableció la categorización de las cuencas hidrográficas, que denominó cuencas regionales, interregionales, nacionales o internacionales, en relación a las características y a la extensión del territorio interesado. Atendiendo 
a esta normativa, la región del Friuli Venezia Giulia comprende tres cuencas de nivel nacional (la de los ríos Tagliamento, Livenza e Isonzo), una de tipo interregional al interesar parte de la región contigua del Veneto (río Lemene), una regional que aglutina a la red de pequeños cursos fluviales abastecidos por aguas de resurgencia y una pequeña cuenca de rango internacional, que se extiende en el extremo nordeste de la región, al formar parte de la cuenca del Danubio. Por otro lado, la gestión del servicio hídrico (captación, potabilización, distribución y depuración de las aguas) compete al denominado «Ambito Territoriale Ottimale» (ATO), gestionado por la Autorità d'Ambito e instituido por la ley no 36 de 1994. El denominado Servicio Hídrico Integrado fue regulado por la ley regional 13/2005, transposición, con bastante retraso, de una normativa nacional, la ley 36/94. Atendiendo a las indicaciones de esta normativa, se procedió a la delimitación de los «ambiti territoriali ottimali», cuatro, uno para cada provincia, más uno de carácter interregional, que interesa a municipios de la provincia de Pordenone y a municipios pertenecientes a la región del Veneto. Si bien hasta finales de 2007 solamente uno está plenamente operativo, que coincide con el territorio de la provincia de Gorizia (Autorità d'Ambito Territoriale Ottimale, 2006); habiendo redactado el Plan de Área, que contiene la programación de las diversas actuaciones a desarrollar por este ente gestor.

Tabla 2. El contexto legal de la planificación hidrológica en ambas regiones

\begin{tabular}{|l|l|}
\hline \multicolumn{1}{|c|}{ Comunidad Valenciana } & \multicolumn{1}{c|}{ Friuli Venezia Giulia } \\
\hline - Ley 29/1985, de aguas. & - Legge de 18 de maggio de 1989, n. 183 \\
- Real Decreto 1664/1998, que aprueba los & - Norme per il riassetto organizzativo e \\
planes hidrológicos. & funzionale della difesa del suolo \\
- Ley 46/1999, Texto Refundido de la Ley de & - Legge de 5 gennaio de 1994, n. 36 - \\
Aguas. & Disposizioni in materia di risorse idriche \\
- Real Decreto Legislativo 1/2001de 20 & - Legge regionale de 23 de junio de 2005, \\
de julio, por el que se aprueba el texto & n. 13 - Organizzazione del servizio idrico \\
refundido de la ley de aguas. & integrato e individuazione degli ambiti \\
- Ley 62/2003, de 30 de diciembre de & territoriali ottimali in attuazione della legge 5 \\
2003, de Medidas Fiscales, Administrativas & gennaio 1994, n. 36 \\
y del Orden Social, que modificó el Texto & - Decreto legislativo de 3 de abril de 2006, n. \\
Refundido de la Ley de Aguas. & 152 - Normas en materia ambiental \\
- Real Decreto 125/2007, de 2 de febrero & - Decreto legislativo de 8 novembre de 2006, \\
por el que se fija el ámbito territorial de las & n. 284 - Disposizioni correttive e integrative \\
demarcaciones hidrográficas & del decreto legislativo 3 aprile 2006, n. 152 \\
- Real Decreto 907/2007, de 6 de julio, por & \\
el que se aprueba el Reglamento de la & \\
Planificación Hidrológica & \\
\hline
\end{tabular}

Elaboración propia

En España, la política de aguas ha sido desarrollada por las Confederaciones Hidrográficas sobre la base de las cuencas hidrográficas como escala básica de 
actuación. Hasta la promulgación de la Ley 29/1985, de Aguas, la consideración que habían merecido los recursos hídricos en la legislación vigente hasta entonces, había estado dominada por las actuaciones hidráulicas dirigidas principalmente al incremento de la oferta de agua. La Ley de Aguas 29/1985 y sus posteriores reformas, han introducido nuevos contenidos que valoran el papel de la gestión de la demanda y de la ordenación del territorio en la política de aguas. La Ley 46/1999, integrada en el Texto Refundido de la Ley de Aguas (TRLA), aprobado por Real Decreto Legislativo 1/2001, contempló nuevos aspectos como el buen estado ecológico de los recursos de agua, las fuentes no convencionales (desalación y reutilización), las políticas de ahorro en regadíos mediante los consumos de referencia, o los contratos de cesión de los derechos al uso privativo de las aguas. Los instrumentos que preveía la Ley de Aguas 29/1985 para la consecución de los objetivos previstos en la citada normativa fueron los planes hidrológicos de cuenca, que fueron aprobados en su mayoría mediante el Real Decreto 1664/1998. Nuevas temáticas han surgido en las últimas modificaciones de las normativas citadas al amparo de cuestiones relacionadas con la participación de los usuarios, la gestión de la demanda o la gobernanza.

\section{LA IMPLEMENTACIÓN DE LA DIRECTIVA MARCO COMUNITARIA: EL BORRADOR CORRESPONDIENTE A LOS ARTÍCULOS 5 Y 6}

La implementación de la directiva marco comunitaria (DMA) evidencia modalidades y tiempos diversos en las dos regiones analizadas, lo que en cierto modo, contradice a la normativa comunitaria (Comisión Europea, 2001). Su aplicación lineal y cronológica se ve dificultada, no solo por cuestiones de tipo normativo (transposición y su articulación con la política hidráulica previa) y ejecutivo (la homogeneidad o heterogeneidad de organismos que deben aplicarla), sino también por la trascendencia que las cuestiones hídricas han desempeñado en las políticas territoriales de cada región, que determina, en gran medida, la mayor o menor disponibilidad de fuentes y documentos sobre esta temática.

El decreto legislativo 152 de 3 de abril de 2006, sobre normas en materia ambiental, incorpora a la legislación italiana las indicaciones de la Directiva Marco, que deroga las normativas anteriores relacionadas con cuestiones ambientales (Legge 431/1985, Galasso, disposizioni urgenti per la tutela delle zone di particolare interesse ambientale) como aquéllas específicas sobre la gestión integrada del agua (legge $n^{\circ}$ 36/1994, Galli, disposizione in materia di risorse idriche). En Friuli, a finales de 2007, una vez «reconvertidos» los «bacini idografici» en demarcaciones, las autoridades hidrográficas están en proceso de revisión de la documentación disponible. Su objetivo es adecuar la planificación vigente a las líneas directrices trazadas por la Directiva Marco del Agua. Debe subrayarse que la falta de armo- 
nización temporal de las fases de aplicación de esta directiva y la existencia de cuencas gestionadas por organismos diversos ${ }^{2}$ han generado dificultades de aplicación y una ralentización en el procedimiento de transposición de la normativa comunitaria a las leyes regionales. La excesiva parcelización de competencias en materia hídrica (ATOs y confederaciones hidrográficas), tanto en el plano legislativo como en el operativo, ha dificultado la ejecución de esta directiva. La tradicional falta de unidad en la gestión del agua, que desde el punto de vista aplicado, conlleva una duplicidad de niveles administrativos, la existencia de numerosas entidades con competencias en materia de agua, demasiados intereses implicados y privilegios adquiridos que deben salvaguardase, implica una mayor complejidad a la hora de gestionar el recurso desde una óptica integrada; además de comportar obstáculos e interrupciones en la aplicación de las etapas previstas en la implementación de la directiva comunitaria, ya que conlleva una integración a medio plazo de las entidades existentes.

En la actualidad, las Autoridades de Cuenca italianas, en retraso en el proceso de implementación de los Planes de Demarcación, así como de diversas actuaciones previstas por la Directiva Comunitaria, han procedido, utilizando los documentos del denominado Plan Parcial de Cuenca $^{3}$ (Piano Stralcio), a elaborar proyectos de gestión específicos para cada uno los cursos de agua para poder dar respuesta a las requerimientos más urgentes. Es el procedimiento que se ha aplicado en las actuaciones adoptadas para evitar las reiteradas inundaciones que, a lo largo de la historia y hasta la actualidad, han afectado al curso bajo del río Tagliamento. La discutida y controvertida solución hidráulica basada en la realización de tres cajas de expansión en el curso medio, aguas abajo de la Cerrada de Pinzano, es la propuesta que el Plan propone. Las comunidades incluidas en el LIC (Red Natura 2000) del curso medio del Tagliamento se han opuesto con firmeza a dichas intervenciones. Argumentan que, por sus dimensiones (altura

2 Las cuencas de los 3 ríos friulanos de nivel nacional (Tagliamento, Lievenza e Isonzo) son gestionados por una única autoridad de demarcación con sede en Venecia que, a su vez, tiene competencias sobre otros importantes cursos de agua de las tres regiones del Noreste italiano (Friuli Venezia Giulia, Veneto y Trentino-AltoAdige), mientras que la cuenca regional denominada Friuli VeneziaGiulia es gestionada por una Dirección General del gobierno del Friuli.

3 Desde el momento que la complejidad de las cuestiones a afrontar a escala integral de la cuenca requiere de escalas de trabajo más prolongadas para implementar un plan de demarcación articulado e integral, el territorio quedaría, por un largo periodo de tiempo, desprovisto de una adecuada gestión y planificación. Para evitar esta situación, se ha adoptado como solución temporal la introducción del concepto de Plan Parcial de Cuenca (Piano Stralcio), que puede interesar tanto a la planificación de una subcuenca como a la planificación de una o más cuestiones específicas en relación a la urgencia con la que sea necesario actuar. 
de los márgenes de contención de las tres cajas y la superficie total interesada), generarán efectos a gran escala, visibles a simple vista. El río, conocido a nivel internacional por la conformación de brazos entrelazados y por su todavía elevado grado de naturalidad, al menos en su curso medio, resultará, con toda probabilidad, ampliamente comprometido. Otro Plan publicado recientemente (noviembre de 2008) es el relativo a la gestión del torrente Cormor, pequeño pero importante curso de agua en relación a la áreas que atraviesa (de media a alta densidad de población y de relevante actividad productiva), en particular, el área metropolitana de Udine, y de los procesos de desbordamiento, que frecuentemente lo caracterizan en el tramo de ingreso en la baja llanura. Las inundaciones acaecidas en 1991 y 1998 se han traducido en la aprobación de normativas en materia de defensa hidráulica de la cuenca. Ello se ha llevado a cabo tras un interesante proceso de participación pública, mediante diversos sistemas de consulta, de los diferentes actores presentes en el territorio, tal y como prevé la ley regional no 16 , de 3 de julio de 2002. Otras iniciativas de planificación específica para determinados cursos fluviales están elaborándose, en las que destacan, a modo de estudios piloto, interesantes modalidades de participación pública y estudios de impacto ambiental.

En España, la normativa comunitaria fue transpuesta mediante la Ley 62/2003, de 30 de diciembre de 2003, de Medidas Fiscales, Administrativas y de Orden Social, que modificó el Texto Refundido de la Ley de Aguas (TRLA), aprobado por el Real Decreto Legislativo 1/2001. El Real Decreto 125/2007 fija el ámbito territorial de las demarcaciones hidrográficas. En la Comunidad Valenciana, una cuestión todavía no resuelta es la revisión del ámbito territorial de la Confederación Hidrográfica del Júcar, establecido por el Real Decreto 650/1987, que incluía todas las cuencas que vertían al mar Mediterráneo entre la desembocadura de los ríos Cenia y Segura. Del nuevo Plan de Cuenca de la Demarcación Hidrográfica del Júcar, que debería entrar en vigor en 2009 en cumplimiento de la Directiva Marco del Agua, deberían quedar excluidas las cuencas intracomunitarias valencianas, si bien, de forma provisional se han adscrito a la Confederación Hidrográfica del Júcar mientras su gestión no sea asumida por la futura Agencia Valenciana del Agua. La consideración del Júcar como cuenca piloto, permitió, no sólo el establecimiento de una metodología, sino sobre todo disponer de una documentación precisa y desarrollada sobre las dinámicas socioeconómicas y su repercusión sobre el recurso agua, lo que se tradujo en una actualización de los datos disponibles en relación a los del Plan Hidrológico de Cuenca aprobado en 1998 (Confederación Hidrográfica del Júcar, 2004). Esta información corresponde en gran medida a la utilizada para la elaboración del borrador requerido por el artículo 5 de la normativa, así como su plasmación en el futuro plan de gestión de la demarcación. 
La primera etapa del proceso de planificación e implementación de la nueva directiva marco en ambas regiones ha sido la caracterización de las demarcaciones y la elaboración de un documento de acuerdo con lo establecido en los artículos 5 y 6 de la Directiva. Éste debe al menos, contener, indicaciones sobre las características de las estructuras físico-ambientales y socio-económicas de cada demarcación, sobre las repercusiones (presiones e impactos) de las actividades humanas sobre los cursos fluviales en términos de calidad del agua y un análisis económico del uso del agua. Los resultados de estos informes fueron notificados a la Comisión Europea en junio de 2005 (región valenciana) y octubre de 2006 (región italiana). La fragmentación de los organismos que ejercen sus competencias sobre las demarcaciones hidrográficas que interesan el territorio del Friuli Venezia Giulia ha comportado necesariamente la elaboración de 3 documentos (Report art.5) para cumplir los requerimientos del artículo 5: uno relativo a las tres cuencas más importantes ha sido llevado a cabo por la Autoridad de Cuenca de los ríos Isonzo-Tagliamento-Livenza-Piave y Brenta-Bacchiglione, un segundo que interesa al río Lemene ha sido realizado por el gobierno regional del Véneto y un tercero, que comprende la cuenca regional, ha sido elaborado por Direzione Centrale Ambiente e Lavori Pubblici del gobierno del Friuli.

La comparación de los documentos elaborados en cumplimento de los artículos 5 y 6 pone de manifiesto que los organismos responsables tratan de adaptarse a los requerimientos que ésta contiene: el esquema ${ }^{4}$ es bastante similar en los tres documentos italianos ${ }^{5}$ y el español (Demarcación del Júcar), pero no del todo homogéneos como consecuencia de los argumentos que cada demarcación considera prioritarios, el nivel de profundidad y detalle con que se afrontan determinadas cuestiones y los documentos disponibles para proceder a la elaboración de estos informes. Un comentario similar es extensible a la documentación cartográfica asociada a la implementación de esta normativa: ésta responde a unos criterios comunes, si bien la información que contiene presenta diferencias significativas. En

4 El esquema, grosso modo, se articula en 4 epígrafes, a saber: a) introducción; b) descripción de las características físico-ecológicas de cada demarcación, donde se analiza la localización y caracterización de las masas de agua; c) repercusiones de las actividades humanas en el estado de las aguas; identificando presiones, fuentes contaminantes y evaluación de los impactos que se completa con una recopilación de estadísticas de calidad de las aguas, sobre suministro y abastecimiento de agua; d) análisis económico del agua, atendiendo a la repercusión de costes y a la caracterización económica del agua.

5 De los tres informes que interesan a esta región, no se ha analizado el correspondiente a la demarcación interregional (río Lemene) al discurrir en su mayor parte por territorio de la región del Veneto. 
todos ellos, la documentación territorial aparece elaborada mediante Sistemas de Información Geográfica, donde las capas de información son las mismas, no lo es tanto los contenidos que albergan con notables diferencias entre unos y otros.

Un análisis detallado de los contenidos de los 3 informes evidencia los contrastes entre unas demarcaciones y otras. La comparación de los epígrafes «análisis económico del agua», «recursos y demandas» y «calidad de las aguas» resulta harto significativa. Su elección no es aleatoria, sino que sintetizan los nuevos planteamientos de la directiva marco en torno al agua, a saber, una adecuada gestión del agua entendida no sólo como recurso económico, sino como portadora de valores de tipo social, ambiental y cultural, el agua entendida como elemento generador de ecosistemas y paisajes vinculados a ella y la sustitución de la política hidráulica tradicional (generación de recursos) por otras orientadas a la planificación demanda.

El análisis económico del agua es uno de los objetivos prioritarios de esta directiva. Este apartado es uno de los puntos fuertes de la memoria elaborada por la Cuenca Hidrográfica del Júcar, que presenta desagregada esta información a diversas escalas y usos (repercusión de costes actuales en usos agrícolas y urbanos del agua, análisis del coste del agua según la procedencia del recurso -superficial, subterráneo, o recursos no convencionales- y datos según usuarios). Los estudios realizados por las dos demarcaciones italianas son más superficiales. Respondiendo, en gran medida, a un comentario genérico de las relaciones entre el agua y la economía a escala nacional o regional, siendo muy escasos, por no decir, nulos los ejemplos a nivel de área de estudio. En el elaborado por la Autorità di Bacino de los ríos Isonzo, Tagliamento, Livenza, Piave y Brenta-Bacchiglione (2006) su grado de desagregación es bastante pobre: incluye los datos regionales, sin diferenciar entre el área objeto de competencia y el resto de la región; indicadores que, en todo caso, son genéricos. Se limita a incluir los cánones, de ámbito nacional, aplicados según diversas tipologías de concesión (uso hidroeléctrico, uso agrícola y abastecimiento). La escasa atención prestada a esta cuestión es más explicita en el informe llevado a cabo por la Región Autónoma del Friuli, pues carece de análisis económico de los usos del agua. La causa, según afirman sus redactores, es la no disponibilidad de los datos necesarios para su elaboración. El heterogéneo tratamiento se relaciona con factores técnicos, pero también de percepción del agua como bien y recurso. La elección del Júcar como cuenca piloto facilitó en su momento la obtención de estos indicadores y el retraso en las italianas. Sin embargo, la diversa trascendencia que ha tenido el recurso agua en ambas regiones es la clave interpretativa. La abundancia 
de caudales y la inexistencia de conflictos entre los usos determinan que en las dos demarcaciones italianas el precio del agua sea en muchos casos un valor fijado por ley, más que por la oferta y la demanda; incluso en las tierra de la baja llanura, bonificadas, los usuarios no pagan por el caudal utilizado, sino un canon, anual, establecido por ley y según superficie, que amortiza, en parte, la impulsión y bombeo que evita el encharcamiento de las tierras. Ello explica el escaso valor asignado al agua como recurso, que se plasma en la exigua atención que este apartado ha tenido en los documentos relativos a la gestión de los recursos hídricos. En cambio, unas demandas crecientes en la Comunidad Valenciana desde los años 60 y unos recursos no distribuidos homogéneamente y con fuertes presiones hacen del agua un recurso muy valioso y con un claro valor, en términos económicos. Las encuestas y los focus group elaborados por los diferentes usuarios reflejan estos contrastes, que en muchas ocasiones, no son más que un reflejo de la percepción que la sociedad en conjunto tiene del recurso agua.

Esa dualidad en el tratamiento del epígrafe «análisis económico del agua» es extensible al que hace referencia a «recursos y demandas». La trascendencia del agua en la Comunidad Valenciana, entendida como elemento generador de riqueza y a su heterogénea distribución en el territorio, explica que siempre haya sido objeto de una atención prioritaria las cuestiones relacionadas con los usos y las demandas de agua; con atención especial en los diferentes subsistemas hídricos (subcuencas). Ello se traduce en un análisis pormenorizado de los recursos disponibles y de los consumos actuales según usos, pero también el estudio de las tendencias a medio plazo; donde las tensiones y conflictos por el tema del agua es un tema prioritario en algunas subcuencas. En cambio, en Friuli, la existencia de unos recursos abundantes ha determinado tradicionalmente que el agua no sea contemplada como un recurso estratégico en el desarrollo socioeconómico del territorio. De hecho, el informe elaborado por el gobierno regional reconoce que la abundancia de recursos favorece un uso poco sostenible de la misma, en ocasiones injustificado, que no responde a criterios de racionalidad económica ni ambiental (Regione Autonoma Friuli Venezia Giulia, 2007b, pág 43). Esta situación se agudiza en la baja llanura, donde la existencia de numerosos pozos privados, unos mantos freáticos próximos a la superficie y el pago de un canon fijo que no contempla el volumen real consumido determina que, por ejemplo, se riegue incluso cuando no es necesario. Ello explica la práctica inexistencia de datos relativos a recursos disponibles y demandas, más allá de meras extrapolaciones y datos a nivel nacional en ambos informes.

La Directiva marco asigna una atención particular al epígrafe «calidad y protección de las masas de agua»; diferenciando entre aquéllas que conservan va- 
lores ambientales, de aquéllas altamente antropizadas. La normativa presta una atención particular a los cursos fluviales en aquellas áreas definidas como áreas protegidas (art. 6). El término «área protegida» no hace referencia, únicamente, a áreas de gran valor ambiental, sino que incluye, por ejemplo, las masas de agua destinadas a abastecimiento urbano. La relevancia asignada a los conceptos de calidad viene en gran medida determinada por la trascendencia que a nivel comunitario adquiere la contaminación de las masas de agua, especialmente en la Europa Central y del Norte. El análisis del epígrafe «calidad de las aguas», a diferencia de los dos anteriores, presenta una documentación más completa y variada en los dos informes elaborados por las autoridades italianas que en el valenciano. En aquéllos, se definen los aspectos cualitativos de todas las masas de agua en relación a sus características físico-químicas y a los impactos generados por las actividades humanas (navegación, agricultura, industria, uso energético y abastecimientos). En esta región, la calidad de las masas de agua adquiere una mayor trascendencia que el de la cantidad que está garantizada. El Friuli es la región italiana con el índice más elevado de empleo de fertilizantes por hectárea cultivada y de los más altos en el uso de funguicidas (ISTAT, 2007a). Estos, junto a otros indicadores, justifican la atención prestada por las autorità di bacino a la calidad del agua, que es considerada como el problema más importante que interesará a la gestión de los recursos hídricos a medio plazo. La contaminación de las aguas derivada de los productos químicos utilizados en la agricultura, especialmente en un área de media-baja llanura, donde los mantos freáticos están próximos a la superficie, puede significar la contaminación de las aguas potencialmente utilizables (tanto para usos agrícolas, pero especialmente para los urbanos, convirtiéndose en recursos no aptos para el consumo humano), así como de áreas de gran valor ecológico-ambiental (lagunas). La calidad no ha sido un tema prioritario en la planificación hidrológica de la cuenca del Júcar (la escasez de recursos y su heterogénea distribución han centrado los objetivos de gestión de las autoridades a lo largo del tiempo); de ahí la menor atención prestada en el borrador que se presentó en 2004 (Estrela et ali, 2004). La trascendencia que esta cuestión reviste en la directiva marco ha determinado que en el documento final (Confederación Hidrográfica del Júcar, 2007) se haya profundizado en este argumento, pero sigue, en algunos casos, siendo poco preciso. En numerosas ocasiones, por ejemplo, se hace una mención genérica a los indicadores recogidos por el Real Decreto del Ministerio (Dirección General del Agua, 2004), pero sin incorporar datos relativos y específicos al área de estudio o en algunos cuadro-síntesis de los impacto sobre las diferentes masas de agua, el termino más frecuente es «sin datos». 


\section{A MODO DE CONCLUSIÓN. LA IMPLEMENTACIÓN DE LA DIRECTIVA MARCO DEL AGUA, UN PROCESO DILATADO Y COMPLEJO}

Los epígrafes anteriores evidencian las dificultades para implementar normativas comunes en ámbitos como la Europa a 27, donde la existencia de realidades físico-ecológicas y socio-económicas diversas, pero también de marcos normativos, determina problemáticas y prioridades diversas. Estos elementos, que puede considerarse como una debilidad a la hora de implementar normativas elaboradas con una óptica global, pueden contribuir a establecer propuestas metodológicas que conduzca a la identificación de los puntos débiles y fuertes de esta normativa comunitaria no tanto desde el punto de vista teórico, sino desde una óptica aplicada. En esta última, es fundamental insistir en las particularidades de los territorios, que condicionan, en numerosas ocasiones, las respuestas de las sociedades ante cuestiones diversas. El agua no es una excepción.

La aplicación lineal y cronológica de la directiva marco del agua se ve dificultada, no sólo por cuestiones de tipo normativo (transposición), ejecutivo (organismo responsable de su ejecución), documental (desagregación de la información disponible), sino también de tipo político. Los intereses contrastados por el recurso agua entre comunidades autónomas por su gestión, y, más concretamente por el control de los organismos de gestión, ralentizan la adopción de medidas que conduzcan a su aplicación. El concepto de gestión integrada de las masas de agua, uno de los objetivos prioritarios de la directiva marco, fácil de aplicar desde una óptica abstracta y generalista, encuentra notables obstáculos a su aplicación desde un punto de vista aplicado, dados los conflictos existentes entre diversas regiones integradas en una misma cuenca. Notables son los desencuentros entre los gobiernos regionales de Castilla-La Mancha y la Comunidad Valenciana por la gestión del Júcar. Estos conflictos se insertan en una coyuntura nacional de fuertes enfrentamientos entre el gobierno central y determinadas autonomías tras la derogación del trasvase del Ebro. Los conflictos tampoco son extraños en la región del Friuli, en este caso entre los diversos organismos implicados en la planificación y gestión de los recursos hídricos (ATO y confederaciones hidrográficas).

En los países más desarrollados, la consideración que merecen los recursos de agua en sus políticas territoriales ofrece una gran diversidad, reflejando en gran medida los factores de disponibilidad y de consumo de agua. La propia Directiva Marco de Aguas 2000/60/CE constituye una apuesta de la Unión Europea por la protección de la calidad de las masas de agua, un grave problema en muchos países de Europa occidental. En cambio, se ha prestado una escasa atención a los problemas de inundaciones, sequías y de escasez de agua que 
padecen muchas regiones del ámbito mediterráneo comunitario, además de olvidar otras cuestiones fundamentales como las fuentes no convencionales, derechos y régimen de uso, participación de usuarios, sobreexplotación de acuíferos, etc. Asimismo, y aunque se asume la necesidad de integrar la protección y la gestión del agua en otros ámbitos de decisión comunitarios como los de energía, transporte, agricultura, turismo y la política regional, lo cierto es que esta Directiva no ha incluido ningún artículo específico sobre ordenación del territorio y recursos hídricos, olvidando incluso citar documentos esenciales como la propia Estrategia Territorial Europea (1999). En efecto, se han primado las cuestiones relativas a la conservación de las masas de agua, junto con una política de precios (Art. 9) para alcanzar unos objetivos ambientales que se establecerán en los nuevos planes hidrológicos de cuenca, que deberán estar finalizados en 2009 (Art. 13).

La Directiva Marco del Agua apuesta por la adopción de unas nuevas directrices orientadas a la adopción de políticas que promuevan una buena gestión del agua como recurso y de los ecosistemas y paisajes vinculados a ella, la sustitución de la política hidráulica tradicional (generación recurso) por otras orientadas a la planificación de la demanda, es decir, se pasa de estrategias de oferta a estrategias de demanda, y una visión holística y ecosistémica del agua, entendida no como un mero recurso económico, sino como portadora de valores de tipo social, ambiental y cultural. Ello conlleva significativos cambios en unas sociedades donde los planteamientos economicistas están ampliamente difundidos y donde las cuestiones ambientales, a pesar de los significativos avances, siguen, en numerosas ocasiones, teniendo un papel secundario.

Se apuesta, asimismo, por la denominada «recuperación íntegra de los costes», es decir, que el precio final contemple los gastos asociados a su extracción, almacenamiento, distribución, sistema recogida y tratamiento, etc., pero también aquéllos asociados a los costes medioambientales y, en particular, de conformidad con el principio de quién contamina paga; entendido como el principio del no deterioro, es decir, profundizando en el compromiso de conservación más allá del principio contaminador-pagador. La recuperación integra de los costes, es decir, la asignación de un valor monetario «real» a un recurso que en numerosas ocasiones viene definido por una fuerte subvención estatal pretende fomentar una utilización de este recurso más eficaz, entendida en términos de racionalización de la demanda y ahorro de recursos. Este objetivo presenta, en la actualidad, realidades notablemente diversas: son las áreas donde los recursos son más escasos, en relación a las demandas o su disponibilidad como consecuencia de factores físicos, donde el precio pagado por el agua se aproxima al denominado «coste integral», lo que ha generado no pocos problemas de ren- 
tabilidad a las actividades agrícolas y de tensiones entre diversos usos; sin olvidar graves problemas medioambientales (sobreexplotación de recursos subterráneos, por ejemplo). Igualmente, son las zonas donde los sistemas de ahorro de agua están más difundidos, dado su escasez y elevado valor monetario. Ello responde en gran medida a la relevancia social, territorial y económica que el agua ha tenido a lo largo de la historia. En cambio, en aquellos territorios con recursos abundantes, el agua ha tenido menor trascendencia territorial y socioeconómica, ya que su disponibilidad estaba garantizada. Su valor, en términos económicos, era menor; la ley de la oferta y la demanda, no era necesaria y consiguientemente, tampoco lo era el ahorro. La implementación de la normativa comunitaria exige el incremento notable del precio del agua; cuestión difícil de entender por amplios colectivos; muchos de los cuales verían reducidos notablemente sus beneficios económicos; además de significar una ruptura bastante notable con la «gestión tradicional del agua», donde el agua es un bien gratuito.

Los informes elaborados por las autoridades valencianas y friulanas reflejan, claramente, el imperativo legal de aplicar una normativa de rango comunitario; que trata de uniformar el tema del agua. Pero, sobre todo, reflejan la diversidad europea, reflejo de las diversas estructuras físico-ecológicas y socio-económicas, que se han plasmado en múltiples sistemas de gestión, utilización y valor cultural del agua, etc., que resultan mucho «más difíciles» de armonizar o, al menos, precisan de marcos temporales más dilatados, que una mera trasposición de una normativa.

\section{BIBLIOGRAFÍA}

Agencia Valenciana de Turismo (2009): El turismo en la Comunidad Valenciana, 2008. Valencia: Conselleria de Turismo (http://www.comunidad-valenciana. org/pdf/turismo_cv_2008.pdf). Fecha consulta: 12 de marzo de 2009.

Arrojo, P. (1999): «La nueva cultura del agua ante el reto de un nuevo plan hidrológico nacional». En Economistas, $n^{\circ}$ 80, pp. 441-450

Autorità d'Ambito Territoriale Ottimale (2006): Piano d'ambito Orientale Goriziano. Gorizia.

Autorità di Bacino dei fiumi Isonzo, Tagliamento, Livenza, Piave, Brenta-BacchiGLIONE (2006): Direttiva 2000/60/CE. Report art. 5, Venezia.

Autorità di Bacino dei fiumi Isonzo, Tagliamento, Livenza, Piave, Brenta-BacchiGLIONE (2004): Tagliamento. Supernova.

Autorità di Bacino Regionale del Friuli Venezia Giulia (2007): Scarsità d'acqua e siccità. Interventi sostenibili in agricoltura e nelle aree urbanizzate, Palmanova/ Udine.

Autorità di Vigilanza sulle Risorse Idriche e sui Rifiuti (2006): Relazione annuale al Parlamento sullo stato dei servizi idrici. Anno 2005, Roma. 
Ayala-Carcedo, F. (1999): «De la política hidráulica a la política del agua sostenible». En Tecnoambiente, $n^{\circ}$ 90, pp. 5-9.

Caixa La (2007): Anuario Económico de España, Varios años, Barcelona: Servicio de Estudios, (http://www.anuarieco.lacaixa.comunicacions.com).Fecha consulta: 12 de marzo de 2009.

Battigelli, F., (2007): «Il Mediterraneo, grande spazio turistico». En Battigelli, F. (ed.). Turismo e ambiente nelle are costiere del Mediterraneo. Regioni a confronto, Udine: Forum, pp. 13-33.

Comisión Europea (2000): Directiva 2000/60/CE del Parlamento Europeo y del Consejo de 23 de octubre, por la que se establece un marco comunitario de actuación en el ámbito de las políticas de agua.

Comisión EuRopea (2001): Common strategy on the implementation of Water Framnework Directive, (http://www.eeb.org/activities/water/Common\%20EU\%20 Strategy\%20for\%20WFD\%20Implementation.pdf). Fecha consulta: 14 de mayo de 2007.

Confederación Hidrográfica del Júcar (1999): Plan Hidrológico de la Cuenca del Júcar. Madrid: Ministerio de Medio Ambiente, (http://www.chj.es/). Fecha consulta: 14 de mayo de 2007.

Confederación Hidrográfica del Júcar (2004): Seguimiento del Plan Hidrológico de la cuenca del Júcar. Madrid: Ministerio de Medio Ambiente.

Confederación Hidrográfica del Júcar (2007): Informe para la Comisión Europea sobre los artículos 5 y 6 de la Directiva Marco del Agua. Valencia: Demarcación Hidrográfica del Júcar, 206 pp. (http://www.phjucar.com/). Fecha consulta: 10 de marzo de 2009.

Dirección General del Agua (2004): Manual para la identificación de las presiones y análisis del impacto en aguas superficiales. Madrid: Ministerio de Medio Ambiente.

Embid Irujo, A. (dir.) (1999): Planificación hidrológica y política hidráulica (El Libro Blanco del Agua). Seminario de Derecho del agua de la Universidad de Zaragoza, Zaragoza: Confederación Hidrográfica del Ebro.

Estela, T.; Fidalgo, A.; Fullana, J.; Maestu, J.; Pérez, M. A. y Pujante, A. M. (2004): Jucar Pilot River Basin. Provisional Article 5 Report. Pursuant to the Water Framework, Valencia: Confederación Hidrográfica del Júcar, 200 pp.

Generalitat Valenciana (2009): Datos básicos del sector agrario valenciano, 2007. Valencia: Conselleria de Agricultura.

GuARAn, A. (2006): «Gestione ed usi delle risorse idriche in un'area ad elevato sviluppo turistico. Il caso della località balneare di Lignano Sabbiadoro». En Grillotti di Giacomo M. G. y Mastroberardino L. (eds.): Geografie dell'acqua. La gestione di una risorsa fondamentale per la costruzione del territorio, Bologna: Pàtron, pp. 973-990. 
Guaran, A. y Di Giusto, L. (2007): «Lignano Sabbiadoro: la città inventata». En Battigelli, F. (ed): Turismo e ambiente nelle aree costiere del mediterraneo. Regioni a confronto. Udine: Ed. Forum, pp. 63-98.

Hernández Hernández, M. (2007): «Grado e l'isola d'oro: dal turismo storico alla maturità». En Battigelli, F. (ed): Turismo e ambiente nelle aree costiere del mediterraneo. Regioni a confronto. Udine: Ed. Forum, pp.35-62.

INE (2001): Censo Agrario de 1999. Madrid: Secretaria General Técnica.

INE (2005): Censo de población y viviendas, 2001 (http://www.ine.es/inebmenu/ mnu_cifraspob.htm). Fecha consulta: 21 de abril de 2009.

INE (2008): Estadísticas sobre medio ambiente. Estadísticas medioambientales sobre el agua. Año 2007. (http://www.ine.es/inebmenu/mnu_medioambiente). Fecha consulta: 28 de abril de 2009.

INE (2009): Padrón de habitantes de la Comunidad Valenciana a 31 de diciembre de 2008. (http://www.ine.es/inebmenu/mnu_cifraspob.htm). Fecha consulta: 21 de abril de 2009.

ISTAT (2003): Statistiche sulle acque, 2000. (http://acqua.istat.it). Fecha consulta: 14 de mayo de 2008.

ISTAT (2005a): Statistiche meteorologiche 2000-2002. Annuari n. 29. Roma.

ISTAT (2005b): $14^{\circ}$ Censimento della popolazione e delle abitazioni (2001). Regione Autonoma Friuli Venezia Giulia (http://www.istat.it/censimenti/popolazione/). Fecha consulta: 14 de mayo de 2008.

ISTAT (2006): Il sistema delle indagini delle acque, «Informazioni n. 16», Roma.

ISTAT (2007a): Statistiche ambientali, 2005 «Annuari n. 9», Roma.

ISTAT (2007b): Statistiche del turismo, 2006. Roma.

Maestu, J.; Calvo, I. y Valderrama, J. (2004): Informe de recuperación de costes de los servicios de agua en el ámbito territorial de la Confederación Hidrográfica del Júcar. Artículo 5. Anejo III. Madrid: Ministerio de Medio Ambiente.

Mencini, G. (2004): L'uomo e il fiume: tra pianificazione territoriale e tutela ambientale. En Autorità di bacino (a cura di), Tagliamento, Supernova.

Moral Ituarte, L. del (2000): «Planificación hidrológica y política territorial en España». En III Congreso Ibérico sobre Gestión y Planificación del Agua, Oporto, 2000. (policopiado 9 p).

Moral, L. del y Saurí, D. (1999): «Changing Course. Water policy in Spain». En Environment, vol. 41 (6), pp. 12-36.

Morales Gil, A.; Rico Amorós, A. M. y Hernández Hernández, M. (2005): «El trasvase Tajo-Segura». En Observatorio Medioambiental, 8, pp. 73-110.

Pérez Cueva, A. (1994): Atlas climàtic de la Comunitat Valenciana, 1961-1990. Valencia: Generalitat Valenciana, 2045 pp. 
Prat, N. (1999): «Ecologia i gestió de l'aigua a Catalunya. Aigua: gestionar l'escassesa», En Medi Ambient, Tecnologia i Cultura, 25, pp. 5-15.

Regione Autonoma Friuli Venezia Giulia (2003): Quinto Censimento Generale dell'Agricoltura, Trieste.

Regione Autonoma Friuli Venezia Giulia (2006): Lirrigazione in Friuli-VeneziaGiulia. Trieste: Direzione Centrale Risorse Agricole, Naturali, Forestali e montagna, $77 \mathrm{pp}$.

Regione Autonoma Friuli Venezia Giulia (2007a): Regione in cifre, Trieste.

Regione Autonoma Friuli Venezia Giulia (2007b): Direttiva 2000/60/CE. Report art. 5, Trieste: Direzione Centrale Ambiente e Lavori Pubblici.

Regione Autonoma Friuli Venezia Giulia (2007c): Warema. Gestione delle risorse idriche nelle aree protette. La consulta di bacino, Udine: Direzione centrale Risorse Agricole Naturali, Forestali e Montagna.

Rico Amorós, A. M. y Hernández Hernández, M. (2008): «Escasez de recursos hídricos, competencia de usos e intensificación de las demandas urbanoturísticas en la Comunidad Valenciana». En Documents d'Analisi Geogràfica, 51, pp. 79-109.

Sumpsi Viñas, J. M, Garrido, A.; Blanco Fonseca, M.; Varela Ortega, C. e Iglesias Martínez, E. (1998): Economía y Política de gestión del agua en la agricultura. Madrid: Mundi-Prensa.

TÀbara, D.; Costejè, M. y Van Woerden, F. (2004): «Las culturas del agua en la prensa español. Los marcos culturales en la comunicación sobre el plan hidrológico nacional» En Papers, Revista de Sociologia, 73, pp. 155-181.

Tello, E. (2001): «Dèficits hídrics o ciutats insostenibles?», En Primeres Jornades Catalanes per una Nova Cultura de l'Aigua, 22 pp.

Tockner K.; Ward, J. V.; Arscott, D. V.; Edwards, P. J.; Kollmann, J. Gurnell, A. M.; Petts, G. E. y Maiolini, B. (2003): «The Tagliamento river: a model ecosystem of European importance». En Aquatic Sciences, 65, pp. 239-253.

Vera Rebollo J.; Casado Díaz J. Mª y Ramón Rodríguez A. B. (2004): «Consideraciones sobre el impacto del Plan Hidrológico Nacional en el sector turístico de la provincia de Alicante». En MELGAREJO ROMERO J. (ed.), Repercusiones socioeconómicas del Plan Hidrológico Nacional en la provincia de Alicante, Alicante: Fundación COEPA, pp. 205-267.

WWF Italia (ed) (2006): Rami intrecciati. Azione locale partecipata in difesa del Tagliamento.

WWF Italia (ed) (2007): Studio preliminare per l'individuazione di alternative alle casse di espansione previste nel medio corso del fiume Tagliamento.

ZanetTi M. (2002): The mouth of river Tagliamento, naturalistic aspects and problems of preservation, Nouva Dimensione: Portogruaro. 